\title{
Skipping breakfast among 8-9 year old children is associated with teacher-reported but not objectively measured academic performance two years later
}

Kylie J. Smith ${ }^{1 *}$, Leigh Blizzard ${ }^{1}$, Sarah A. McNaughton², Seana L. Gall ${ }^{1}$, Monique C. Breslin ${ }^{1}$, Melissa Wake $3,4,5$ and Alison J. Venn ${ }^{1}$

\begin{abstract}
Background: Skipping breakfast, habitually and when experimentally manipulated, has been linked in the shortterm to poorer academic performance in children. Little is known about the longer-term effects. This study examined whether skipping breakfast at aged 8-9 years predicted poorer academic performance and classroom behavior 2 years later.

Methods: The Longitudinal Study of Australian Children (LSAC) collected data during 2008 (aged 8-9 years) and 2010 (aged 10-11 years). Breakfast consumption was reported by a parent/caregiver on three occasions within 4 weeks during 2008: by face-to-face interview and two subsequent questionnaires. Children who skipped breakfast on at least one of the 3 days were classified as breakfast skippers. During 2010, the child's teacher assessed their academic performance relative to other children in the same grade (below/far below average; average; above/far above average) and classroom behavior. Objective literacy and numeracy outcomes (reading, writing, spelling, grammar and numeracy, score range 0-1000) were obtained via linkage to Australian standardized national assessment program (NAPLAN) data in Year 5 (aged 10-11 years). Ordinal and linear regression were used, adjusted for sex, age and sociodemographic variables.

Results: At baseline, 243 (10.7\%) of the 2280 children skipped breakfast on at least 1 day. Two years later, breakfast skippers were more likely to have poorer teacher-reported reading (RR: 1.18; 95\% Cl: 1.08, 1.29), mathematics (RR: 1.11; $95 \% \mathrm{Cl}: 1.02,1.20$ ) and overall academic achievement (RR: 1.15; $95 \%$ Cl: 1.05, 1.25) than non-skippers. In contrast, differences in objective NAPLAN scores were small $(<3 \%)$, and only one of the five scales (numeracy) was significantly lower among skippers (mean difference - 13.0; 95\% Cl: -25.6, -0.8). Classroom behavior was similar between skippers and non-skippers.

Conclusion: In this national sample of 8-9 year old Australian children, skipping breakfast occurred at low levels, and showed little association with measured academic performance 2 years later. This contrasted with teacher perceptions of lower academic performance among skippers than non-skippers, most likely reflecting confounding. This underscores the importance of using objective measures of academic performance to avoid inflated effect estimates and, potentially, unnecessary and costly population interventions to increase breakfast consumption.
\end{abstract}

Keywords: Skipping breakfast, Academic performance, Behavior, Longitudinal, School, Breakfast

\footnotetext{
* Correspondence: K.J.Smith@utas.edu.au

${ }^{1}$ Menzies Institute for Medical Research, University of Tasmania, Private Bag

23, Hobart, TAS 7000, Australia

Full list of author information is available at the end of the article
} 


\section{Background}

Skipping breakfast has been linked to reductions in cognition and academic performance [1-3], resulting in strong arguments for public health interventions to increase breakfast consumption. However, well-designed randomized controlled trials (RCTs) [4-6] do not provide convincing evidence of benefit to support the substantial costs of school breakfast programs.

Experimental evidence indicates that, on any given day, skipping breakfast lowers cognitive and academic performance [3]. A systematic review, published in 2009, included 45 studies that examined the association between skipping breakfast and cognitive performance, including memory, attention and test grades. The review focused on school-aged children but the age of participants ranged from 3 years to a mean age of 21 years. The authors concluded that eating breakfast generally had a positive effect on cognitive performance [2]. The beneficial effects of eating breakfast were stronger when testing occurred later in the morning, when tests were more demanding and error rate was considered, and in malnourished populations [2]. In most studies, cognitive performance was assessed within $12 \mathrm{~h}$ of eating/skipping breakfast [2].

The long-term effects of skipping breakfast are less clear. A 2013 review examined the association between skipping breakfast and classroom behavior or academic performance (school grades or standardized achievement tests) among children and adolescents (aged 5 to 19 years) [1]. Five of the eight studies that examined habitual breakfast consumption reported a beneficial association with academic performance. Only one study used a longitudinal design [7], involving 21,400 5-year old USA children followed for 10 years. In contrast to the cross-sectional studies, frequency of breakfast consumption was not significantly associated with standardized test scores for reading, mathematics and science or teacher-reported behavior after adjusting for a wide range of potential confounders [7]. However, breakfast was defined as eating breakfast with the family, so children who ate breakfast alone or at school would be misclassified as breakfast skippers.

School breakfast programs are being implemented to increase breakfast consumption. Despite their popularity, there is little evidence to support their effectiveness. Three well-designed trials found programs that made school breakfast available to all children, did not improve academic achievement or classroom behavior among elementary school children (aged 4-14 years) [4-6]. However, none of the trials increased breakfast consumption among children who normally skipped breakfast; instead, children who usually ate breakfast at home ate it at school.
RCTs are the gold standard for determining causation but pose substantial challenges in this field. Most crosssectional studies did not control for socioeconomic status (SES) [1], which is an important predictor of both academic performance [8] and breakfast consumption $[9,10]$. Data examining the long-term effect of breakfast consumption on academic performance are sparse. Using data from a national study of Australian children, this study examines whether skipping breakfast at age 8-9 years predicts poorer academic performance and classroom behavior 2 years later. We hypothesize that breakfast skippers will have poorer school performance and classroom behavior than those who eat breakfast.

\section{Methods}

Children were recruited for Growing up in Australia: the Longitudinal Study of Australian Children (LSAC) during 2004, aged 4-5 years (Wave $1, N=4983$ ). The sampling frame was extracted from the enrolment database of Medicare, the national health care scheme in Australia that enrolls $98 \%$ of Australian residents by 1 year of age [11]. The children were selected using a two-stage design [11]. In the first stage, postcodes were stratified by state/territory and urban/rural location to ensure geographical representation. Very remote postcodes were excluded. Postcodes were then randomly selected. In the second stage, a $10 \%$ sample of children born between March 1999 and February 2000 were randomly selected. For each postcode, children were listed according to date of birth, and a systematic random sample was taken from this list to ensure a representative range of birth dates.

The response rate at baseline was 54\% $(N=4983)$. Data are collected biennially, with a core face-to-face home visit supplemented by a range of additional measures and data linkages. Data used in this analysis were collected via three mechanisms: home-based faceto-face interview and two subsequent written questionnaires completed by a parent/caregiver at wave 3 (2008); questionnaires completed by teachers at wave 3 (2008) and wave 4 (2010); and linked data from the Australian National Assessment Program - Literacy And Numeracy (NAPLAN), the national standardized school assessment program (Additional file 1: Figure S1). The children were 8-9 years old at wave 3 (participation rate $87 \%$ of wave 1 ) and 10-11 years at wave 4 (participation rate $84 \%$ of wave 1, Fig. 1).

The analysis of confidentialized LSAC data had the approval of the Australian Institute of Family Studies ethic committee. Consent to participate in the study was given by a parent at wave 1 and permission to link with the child's NAPLAN results at wave 3 (or wave 4, if the child did not participate in wave 3 ). 


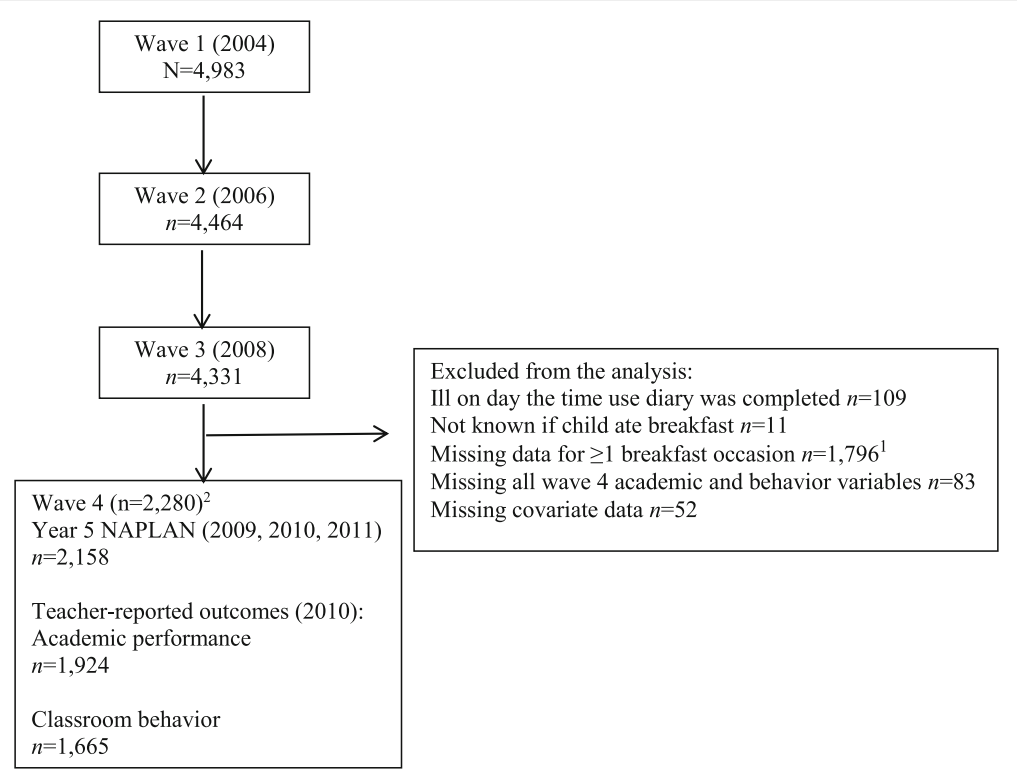

Fig. 1 Participation at each wave of the Longitudinal Study of Australian Children and the final sample. ${ }^{1} 1488$ of these children (those with breakfast data from the interview and one diary) were included in a sensitivity analysis. ${ }^{2}$ Numbers for each outcome do not equal the total sample number due to missing data

\section{Breakfast (wave 3)}

Breakfast consumption was assessed on three occasions, within 4 weeks, at wave 3 (baseline for this analysis). At the face-to-face interview, the parent/caregiver was asked "Did <study child> eat breakfast today?" After the interview, parents were asked to complete two time-use diaries on specified days the following week (one weekday and one weekend day), to which was appended a set of short dietary questions including whether the child had eaten breakfast that day. If the diary was not completed on the allocated date, the parent was asked to wait until the same day the following week. Parents reported whether the child was ill the day the diary was completed. The diaries were collected by the interviewer in person or returned by post. No data on breakfast consumption were collected at wave 4 .

Children who skipped breakfast on at least one of the 3 days were classified as breakfast skippers and compared with those who ate breakfast on all three occasions (nonskippers). Further categorization was not possible because so few children skipped breakfast more than once $(n=17)$.

\section{Academic performance (wave 4 teacher report, year 5 academic testing)}

A questionnaire was sent to the child's teacher as soon as feasible after the wave 4 home interview [12], and on average, was completed 2 months after the interview. Questionnaires were completed for 3269 children (response rate 75.6\%). The teacher was asked to compare the child's reading, mathematics and overall progress to other children of the same level, on a 5-point scale.
Response options were collapsed into three categories for the analysis: "far below/below average", "average", "above/ far above average".

NAPLAN assesses all Australian students in Years 3, 5, 7 and 9 (aged 8-9, 10-11, 12-13, and 14-15 years, respectively) across four domains: reading, writing, language conventions (spelling, grammar and punctuation), and numeracy, using national tests held on the same day in May across Australia each year. Scores are standardized to range from 0 to 1000 for each test, enabling comparisons within and across school year levels [13]. NAPLAN data for 4159 children were linked to the LSAC dataset (98.4\% of those who consented to NAPLAN access, $83.5 \%$ of the total sample at wave 1 ). Of those who were not matched, 552 were not asked for consent as they did not participate in wave 3 or wave 4 , 117 forms were completed incorrectly, 68 could not be linked and 48 refused permission [13]. Because the children did not all begin school in the same year, the Year 5 NAPLAN tests were completed in 2009, 2010 or 2011. For children who repeated a grade and sat the same NAPLAN test more than once, the latest score was used. NAPLAN data were available for 2158 children included in this analysis.

\section{Classroom behavior (wave 4)}

The child's teacher was asked to complete the Strengths and Difficulties Questionnaire (SDQ, Robert Goodman 1999, UK) in relation to the child's classroom behavior. The SDQ includes 25 attributes, with the response options 'not true', 'somewhat true' and 'certainly true'. 
The three scales recommended for low-risk or general population samples were used: internalizing problems (emotional + peer symptoms, 10 items, range 0-20), externalizing problems (conduct + hyperactivity symptoms, 10 items, range 0-20) and prosocial behavior (5 items, range 0-10) [14]. Lower scores for internalizing and externalizing problems and a higher score for prosocial behavior indicate better behavior. Children missing any of the subscale scores were excluded from the analysis.

\section{Covariates (wave 3)}

Covariates considered for inclusion in the adjusted models included sociodemographic variables associated with skipping breakfast (described below) and the other outcome variables (teacher-reported performance, classroom behavior, and the standardized tests; for example the behavior variables were considered as covariates in the analysis examining the association between skipping breakfast and academic performance). The child's age in months was recorded at the face-to-face interview and the NAPLAN tests. A continuous variable for SES was created from standardized scores for three variables: parents' years of education; parents' occupation as determined by the status of their main occupation; and combined annual income including pensions and allowances before tax (with natural $\log$ transformation) [15]. The primary caregiver reported their own health (excellent, very good, good, fair, poor); whether they currently smoked cigarettes (yes/no), whether the child had two parents living at home (yes/no) and the child's ethnicity. Financial hardship was assessed using the Family Hardship Scale, which sums the number of positive responses to seven indicators of household hardship. To calculate the Family Hardship Scales, parent/caregivers were asked to report if they had experienced any of the following situations in the previous 12 months because they were short of money: inability to pay bills on time; unable to pay mortgage or rent on time; went without meals; were unable to heat or cool the home; pawned or sold something because needed cash; sought assistance from welfare or community organization; unable to send child to kindergarten/preschool/child care for as much time as they would like (potential score 0-7) [16]. Ethnicity was considered as a potential confounder in the analysis, but was not included in any of the final models as it did not change the coefficient of breakfast skipping by at least 10\% (our criterion for including a potential confounder [17]) when included in the model. Year 3 NAPLAN test results were used in the propensity model.

\section{Statistical analysis}

Log-link ordinal regression [18] was used to compare the probability of being in a lower level of teacher-reported scholastic performance for skippers and non-skippers. Results are reported for the continuation ratio probability model because for this model a test of the constraint underlying the ordinal assumption was satisfied in most cases. Differences between skippers and non-skippers in mean scores on the behavior subscales and NAPLAN results were estimated using linear regression. Model 1 included adjustment for age and sex. The teacher reported outcomes were adjusted for age at the time of the face-toface interview, and the NAPLAN results were adjusted for age at the time the child sat the test. Model 2 had additional adjustment for SES, which was associated with both skipping breakfast and poorer academic performance. The other covariates included in model 3 were those that changed the coefficient of the covariate for skipping breakfast by at least $10 \%$ [17].

Inverse propensity weighting was used to take into account data missing from the baseline sample. The propensity model included baseline variables associated with missingness: SES; the primary caregiver's sex, selfreported health status, education level and smoking status; household income; two-parent home; financial hardship; change in primary caregiver, child academic achievement (teacher-report and Year 3 NAPLAN) and child school attendance at wave 3. To ensure a full set of weights, missing observations in the variables required by each propensity model were imputed using multiple imputations by chained equations [19]. Ten imputations were performed.

A sensitivity analysis was conducted using only two measures of breakfast (the parent interview and one time-use diary) to allow children who were missing one diary to be included in the analysis. For children who had both diaries, one diary was randomly selected. We also examined cross-sectional associations between skipping breakfast and the wave 3 teacher-reported outcomes (collected the same way as in wave 4), but not the national standardized tests because most children sat the tests (May 2008) before the breakfast data were collected (March-December 2008, Additional file 1: Figure S1).

All analyses were conducted using Stata SE (version 12.1, 2011, StataCorp, College Station, TX). P-values $\leq 0.05$ were considered statistically significant.

\section{Results}

Of the 4331 eligible children, 2280 were included in the main analysis (Fig. 1). About one quarter of the children completed the Year 5 NAPLAN tests in $2009(n=500,23.0 \%$ of the non-skippers and $24.5 \%$ of the skippers), the majority in 2010 ( $n=1551,71.9 \%$ non-skippers, 71.6\% skippers), and 106 in 2011 (5.0\% non-skippers, 3.9\% skippers).

Compared with children who were included in the main analysis, those not included were more likely to have skipped breakfast on the day of the face-to-face interview (2.8\% versus $6.7 \%$, respectively, Additional file 1: Table S1) and to have greater SES disadvantage, poorer 
teacher reported academic performance and behavior, and lower NAPLAN scores (Additional file 1: Table S1).

The prevalence of skipping breakfast was similar between boys and girls: 113 (9.6\%) boys and 113 (10.3\%) girls skipped on 1 day, $10(0.9 \%)$ boys and six $(0.6 \%)$ girls skipped on 2 days, and one boy $(0.1 \%)$ skipped all 3 days. Compared with non-skippers, a higher proportion of breakfast skippers were Indigenous, or from one-parent families (Table 1). However, there were few Indigenous children in the study sample $(n=31,1.4 \%)$ so these findings may not be generalizable to the Indigenous population.

Mean \pm SD follow-up time was $2.03 \pm 0.18$ years. In the adjusted analysis, children who skipped breakfast at baseline were $18 \%$ (reading), $11 \%$ (mathematics) and $15 \%$ (overall achievement) more likely to be in a lower category for all three teacher-reported education outcomes at follow-up (Table 2). Breakfast status was not associated with classroom behavior (Table 3).

The mean scores for all Year 5 NAPLAN domains (potential score range 0-1000) were consistently marginally lower among skippers than non-skippers, with differences in scores ranging from 6.2 for writing to 18.6 for numeracy in the unadjusted analysis (Table 4). The associations were attenuated after adjusting for SES and other covariates. In the final model, the differences in scores between skippers and non-skippers were less than 3\% (range 0.8 for writing to 13.0 for numeracy).

\section{Sensitivity analysis}

Defining breakfast status from two reports of breakfast ( $n=2768$ children, $7.4 \%$ were breakfast skippers) did not substantially change the magnitude or significance of the results (data not shown). Teacher-reported academic performance (Additional file 1: Table S2) and behavior (Additional file 1: Table S3) were similar between skippers and non-skippers in the cross-sectional analysis.

\section{Discussion}

In this sample of Australian children, those who skipped breakfast aged 8-9 years tended to have poorer teacherreported academic performance than non-skippers 2

Table 1 Baseline characteristics of breakfast skippers and breakfast consumers, aged 8-9 years $(N=2280)$

\begin{tabular}{|c|c|c|c|c|c|}
\hline \multirow[b]{2}{*}{ Characteristic } & \multicolumn{2}{|c|}{$\begin{array}{l}\text { Never skipped } \\
(n=2037)^{\mathrm{b}}\end{array}$} & \multicolumn{2}{|c|}{$\begin{array}{l}\geq 1 \text { skip }^{\mathrm{a}} \\
(n=243)^{\mathrm{b}}\end{array}$} & \multirow[t]{2}{*}{$P$-value ${ }^{c}$} \\
\hline & $\bar{n}$ & (\%) & $n$ & (\%) & \\
\hline \multicolumn{6}{|l|}{ Child's sex } \\
\hline Male & 1057 & $(89.5)$ & 124 & $(10.5)$ & \\
\hline Female & 980 & $(89.2)$ & 119 & $(10.8)$ & 0.800 \\
\hline \multicolumn{6}{|l|}{ Ethnicity } \\
\hline Non-Indigenous & 2012 & $(89.5)$ & 236 & $(10.5)$ & \\
\hline Indigenous & 24 & $(77.4)$ & 7 & (22.6) & 0.030 \\
\hline \multicolumn{6}{|l|}{ Sex of primary caregiver } \\
\hline Male & 79 & $(86.8)$ & 12 & $(13.2)$ & \\
\hline Female & 1958 & $(89.5)$ & 231 & (10.6) & 0.425 \\
\hline \multicolumn{6}{|l|}{ Socio-economic status (SES) ${ }^{d}$} \\
\hline Most disadvantaged SES quartile & 398 & $(87.5)$ & 58 & $(12.5)$ & \\
\hline Least disadvantaged SES quartile & 418 & $(90.9)$ & 44 & $(9.1)$ & 0.098 \\
\hline \multicolumn{6}{|l|}{ Mother completed high school } \\
\hline No & 673 & $(87.7)$ & 94 & $(12.3)$ & \\
\hline Yes & 1353 & $(90.3)$ & 146 & $(9.7)$ & 0.066 \\
\hline \multicolumn{6}{|l|}{ Father completed high school } \\
\hline No & 764 & $(88.7)$ & 98 & $(11.3)$ & \\
\hline Yes & 1070 & $(91.1)$ & 109 & $(8.9)$ & 0.082 \\
\hline \multicolumn{6}{|l|}{ Two parent home } \\
\hline No & 183 & $(82.4)$ & 39 & (17.6) & \\
\hline Yes & 1854 & (90.1) & 204 & (9.9) & $<0.001$ \\
\hline
\end{tabular}

${ }^{a}$ Breakfast consumption was reported by a parent/caregiver on three separate days: by face-to-face interview and two subsequent time use diaries

${ }^{b}$ Numbers do not always equal the total sample number due to missing data

${ }^{c} P$-values calculated by chi-square analyses

${ }^{\mathrm{d}}$ Socioeconomic status quartiles are based on the distribution of the Longitudinal Study of Australian Children data 
Table 2 Longitudinal associations between skipping breakfast aged 8-9 years and teacher-reported academic performance aged 10-11 years $(N=1924)$

\begin{tabular}{|c|c|c|c|c|c|c|}
\hline \multirow{2}{*}{$\begin{array}{l}\text { Outcome and } \\
\text { category of skipping } \\
\text { breakfast }\end{array}$} & Above average ${ }^{a}$ & Average $^{a}$ & Below average $^{a}$ & Model $1^{\mathrm{b}}$ & Model $2^{c}$ & Model $3^{d}$ \\
\hline & $n(\%)$ & $n(\%)$ & $n(\%)$ & RR $(95 \% \mathrm{Cl})$ & RR $(95 \%$ Cl) & $\mathrm{RR}(95 \% \mathrm{Cl})$ \\
\hline \multicolumn{7}{|l|}{ Reading progress } \\
\hline Never skipped & $760(44.5)$ & $694(40.6)$ & $254(14.9)$ & 1.00 (ref) & 1.00 (ref) & 1.00 (ref) \\
\hline$\geq 1$ skips & 77 (37.4) & $90(43.7)$ & 39 (18.9) & $1.15(1.05,1.26)$ & $1.14(1.05,1.24)$ & $1.18(1.08,1.29$ \\
\hline$P$-value & & & & 0.002 & 0.002 & 0.001 \\
\hline \multicolumn{7}{|l|}{ Mathematics progress } \\
\hline Never skipped & 705 (41.6) & $748(44.2)$ & $241(14.2)$ & 1.00 (ref) & 1.00 (ref) & 1.00 (ref) \\
\hline$\geq 1$ skips & 79 (38.5) & $88(42.9)$ & $38(18.5)$ & $1.11(1.01,1.22)$ & $1.11(1.03,1.22)$ & $1.11(1.02,1.20$ \\
\hline$P$-value & & & & 0.024 & 0.011 & 0.017 \\
\hline \multicolumn{7}{|l|}{ Overall achievement } \\
\hline Never skipped & $732(43.0)$ & $777(45.7)$ & $192(11.3)$ & 1.00 (ref) & 1.00 (ref) & $-^{\mathrm{e}}$ \\
\hline$\geq 1$ skips & 80 (38.6) & $93(44.9)$ & $34(16.4)$ & $1.14(1.04,1.25)$ & $1.15(1.05,1.25)$ & - $^{\mathrm{e}}$ \\
\hline$P$-value & & & & 0.007 & 0.002 & \\
\hline
\end{tabular}

${ }^{a}$ Comparisons are to other children of the same grade level, calculated using log-link ordinal regression. Below average = below/far below average; Above average = above/far above average

${ }^{\mathrm{b}}$ Model 1: adjusted for sex and age at time of the parent interview

'Model 2: adjusted for sex, age at time of the parent interview and SES (measured at Wave 3)

${ }^{\mathrm{d}}$ Model 3: Model 2 plus the following additional covariates reading progress - teacher reported prosocial behavior at W4; mathematics progress - financial hardship

${ }^{\mathrm{e}}$ There was no model 3 for overall achievement as none of the additional covariates changed the coefficient of the covariate for skipping breakfast by at least $10 \%$

Table 3 Longitudinal associations between skipping breakfast aged 8-9 years and teacher-reported behavior aged 10-11 years $(N=1665)$

\begin{tabular}{|c|c|c|c|c|c|}
\hline \multirow{2}{*}{$\begin{array}{l}\text { Behavior } \\
\text { subscale and category } \\
\text { of skipping breakfast }\end{array}$} & \multirow[b]{2}{*}{$n$} & \multirow[b]{2}{*}{ Mean $\pm S D^{a}$} & \multirow{2}{*}{$\begin{array}{l}\text { Model 1 } \\
\text { Diff }(95 \% \text { Cl) }\end{array}$} & \multirow{2}{*}{$\begin{array}{l}\text { Model } 2^{c} \\
\text { Diff }(95 \% \text { Cl) }\end{array}$} & \multirow{2}{*}{$\begin{array}{l}\text { Model } 3^{\text {d }} \\
\text { Diff }(95 \% \text { Cl) }\end{array}$} \\
\hline & & & & & \\
\hline \multicolumn{6}{|l|}{ Internalizing problems } \\
\hline Never skipped & 1481 & $2.22 \pm 2.92$ & 0 (ref) & 0 (ref) & 0 (ref) \\
\hline$\geq 1$ skips & 177 & $2.40 \pm 3.03$ & $0.35(-0.30,1.00)$ & $0.28(-0.32,0.88)$ & $0.17(-0.74,1.07)$ \\
\hline$P$-value & & & 0.29 & 0.36 & 0.72 \\
\hline \multicolumn{6}{|l|}{ Externalizing problems } \\
\hline Never skipped & 1481 & $2.85 \pm 3.52$ & 0 (ref) & 0 (ref) & 0 (ref) \\
\hline$\geq 1$ skips & 177 & $3.08 \pm 3.69$ & $1.73(-1.28,4.74)$ & $1.13(-1.46,3.71)$ & $0.14(-0.37,0.64)$ \\
\hline$P$-value & & & 0.26 & 0.39 & 0.60 \\
\hline \multicolumn{6}{|l|}{ Prosocial behavior } \\
\hline Never skipped & 1486 & $7.97 \pm 2.17$ & 0 (ref) & 0 (ref) & 0 (ref) \\
\hline$\geq 1$ skips & 179 & $7.66 \pm 2.21$ & $-0.31(-0.58,-0.05)$ & $-0.26(-0.51,-0.01)$ & $-0.26(-0.56,0.03)$ \\
\hline$P$-value & & & 0.02 & 0.04 & 0.08 \\
\hline
\end{tabular}

${ }^{a}$ Values are the unadjusted mean \pm SD score for the three scales of the Strengths and Difficulties Questionnaire. Better behavior is indicated by lower scores for internalizing problems (range 0 - 18) and externalizing problems (range 0 - 20) and higher scores for prosocial behavior (range 0 - 10)

${ }^{\mathrm{b}}$ Model 1: adjusted for sex and age at interview

${ }^{\mathrm{C}}$ Model 2: adjusted for sex, age at interview and SES (measured at Wave 3)

${ }^{\mathrm{d}}$ Model 3: Model 2 plus the following additional covariates internalizing problems - two-parent home, self-reported health of primary caregiver, smoking status of primary caregiver, financial hardship, reading progress; externalizing problems - self-reported health of primary caregiver, smoking status of primary caregiver, financial hardship, reading progress; prosocial behavior - two parent home, reading progress eDifferences between breakfast skippers and breakfast eaters were calculated using linear regression 
Table 4 Longitudinal associations between skipping breakfast aged 8-9 years and national standardized test (Year-5 NAPLAN) results $(N=2158)$

\begin{tabular}{|c|c|c|c|c|c|}
\hline \multirow{2}{*}{$\begin{array}{l}\text { NAPLAN } \\
\text { variable and category } \\
\text { of skipping breakfast }\end{array}$} & \multirow[b]{2}{*}{$n$} & \multirow[b]{2}{*}{ Mean $\pm S D^{a}$} & \multirow{2}{*}{$\begin{array}{l}\text { Model 1 } \\
\text { Diff }(95 \% \text { Cl) }\end{array}$} & \multirow{2}{*}{$\begin{array}{l}\text { Model } 2^{c} \\
\text { Diff }(95 \% \text { Cl) }\end{array}$} & \multirow{2}{*}{$\begin{array}{l}\text { Model 3d } \\
\text { Diff }(95 \% \text { Cl) }\end{array}$} \\
\hline & & & & & \\
\hline \multicolumn{6}{|l|}{ Reading } \\
\hline Never skipped & 1923 & $520 \pm 79.4$ & 0.00 (ref) & 0.00 (ref) & 0.00 (ref) \\
\hline$\geq 1$ skips & 227 & $510 \pm 82.1$ & $-15.3(-27.2,-3.3)$ & $-10.7(-21.4,0.02)$ & $-9.2(-19.7,1.3)$ \\
\hline$P$-value & & & 0.01 & 0.05 & 0.09 \\
\hline \multicolumn{6}{|l|}{ Writing } \\
\hline Never skipped & 1904 & $502 \pm 69.2$ & 0.00 (ref) & 0.00 (ref) & 0.00 (ref) \\
\hline$\geq 1$ skips & 225 & $500 \pm 64.1$ & $-6.2(-15.5,3.1)$ & $-2.1(-10.8,6.5)$ & $-0.8(-9.5,7.9)$ \\
\hline$P$-value & & & 0.19 & 0.63 & 0.86 \\
\hline \multicolumn{6}{|l|}{ Spelling } \\
\hline Never skipped & 1922 & $502 \pm 65.8$ & 0.00 (ref) & 0.00 (ref) & 0.00 (ref) \\
\hline$\geq 1$ skips & 227 & $496 \pm 69.1$ & $-10.3(-20.8,0.2)$ & $-7.4(-17.2,2.5)$ & $-6.0(-15.8,3.8)$ \\
\hline$P$-value & & & 0.05 & 0.14 & 0.23 \\
\hline \multicolumn{6}{|l|}{ Grammar } \\
\hline Never skipped & 1922 & $528 \pm 79.2$ & 0.00 (ref) & 0.00 (ref) & 0.00 (ref) \\
\hline$\geq 1$ skips & 227 & $520 \pm 93.8$ & $-17.4(-31.8,-3.0)$ & $-12.8(-25.7,0.1)$ & $-10.7(-23.6,2.1)$ \\
\hline$P$-value & & & 0.02 & 0.05 & 0.10 \\
\hline \multicolumn{6}{|l|}{ Numeracy } \\
\hline Never skipped & 1917 & $513 \pm 70.5$ & 0.00 (ref) & 0.00 (ref) & 0.00 (ref) \\
\hline$\geq 1$ skips & 227 & $502 \pm 84.1$ & $-18.6(-32.7,-4.5)$ & $-14.2(-26.9,-1.6)$ & $-13.0(-25.6,-0.8)$ \\
\hline$P$-value & & & 0.01 & 0.03 & 0.04 \\
\hline
\end{tabular}

NAPLAN National Assessment Program - Literacy And Numeracy, SES socioeconomic status

${ }^{a}$ Values are the unadjusted mean \pm SD score for each domain of the NAPLAN assessments. Possible score range 0-1000, higher scores indicate better academic performance

${ }^{b}$ Model 1: adjusted for age and sex

${ }^{\mathrm{C}}$ Model 2: adjusted for age, sex and SES (measured at Wave 3)

${ }^{\mathrm{d}}$ Model 3: Model 2 plus the following additional covariates: Reading - smoking status of primary caregiver; Writing - smoking status of primary caregiver, selfreported health of primary caregiver; Spelling smoking status of primary caregiver, two-parent home status; Grammar - smoking status of primary caregiver,

financial hardship; Numeracy - smoking status of primary caregiver

eDifferences between breakfast skippers and breakfast eaters were calculated using linear regression

years later. However objective standardized tests showed the differences were marginal, generally not statistically significant, and attenuated after adjusting for SES. Although a weakly significant difference between breakfast skippers and non-skippers was observed in one of the five NAPLAN scales (Numeracy, $p=0.04$ ), the difference between the two groups was less than $3 \%$ and unlikely to be of great importance. Skipping breakfast was not associated with classroom behavior.

A meaningful difference for NAPLAN has not been defined. In the adjusted analysis, we found breakfast skippers had a 13-point lower score in the Year 5 numeracy test than non-skippers. Every year the national NAPLAN results are reported for each test, stratified by a variety of sociodemographic variables [20]. To put our observed difference into context, the national NAPLAN report showed a similar difference for sex, with the mean Year 5 numeracy score being 11 points higher among boys than girls [20]. Compared to children living in metropolitan areas, those from provincial areas had a 16-point lower numeracy score, and those from remote and very remote areas had a 31-33 point lower score [20]. Larger differences were observed in the national data for parent education, compared to those who had a parent with a university degree, mean Year 5 numeracy scores were 31 points lower among those whose parent had a diploma and 46 points lower among those whose parents had only completed year 12 [20].

This work builds on previous cross-sectional studies by examining the effect of skipping breakfast on academic performance 2 years later. National standardized tests gave an objective measure of academic performance, in addition to the teacher-reported outcomes. Data on skipping breakfast were collected over three nonconsecutive days, allowing us to better capture intermittent skippers than would be possible with a single day's 
measure. To reduce the possibility that skipping breakfast was due to feeling unwell, children were excluded from the analysis if they were reported to be ill on any of the days breakfast consumption was assessed using the time use diary. The large national sample is also a strength of this study.

There are several limitations that need to be considered. The proportion of children who skipped breakfast was low, with a very small number of children skipping breakfast on more than one occasion. Our results may not be generalizable to populations where children regularly go without breakfast. It is likely that skipping breakfast will increase in the LSAC cohort in adolescence for a range of psychosocial reasons and, with repeated follow-ups, different patterns of association may emerge. Stronger associations with academic performance may be observed in children who regularly skip breakfast. However, consistent skipping was very rare and intermittent skipping better reflects what was occurring in this age group. Breakfast data were collected over 3 days. While this allowed us to identify intermittent skippers better than would have been possible with data collected on just 1 day, this may still not fully reflect children's usual breakfast habits. The children who usually skip breakfast one out of 3 days may go to school without breakfast one or 2 days each week but other children classified as skippers may go without breakfast less frequently. We were unable to examine change in breakfast habits in this analysis as breakfast consumption was not assessed at follow-up, and it is possible that children's breakfast habits may have changed during the 2-year follow-up. Future research should examine whether becoming a breakfast skipper is associated with poorer performance on standardized tests or if becoming a breakfast eater is associated with improved standardized test results. Breakfast consumption was reported by parents and there is the possibility of misreporting due to social desirability bias. However, LSAC - a convenient data source to examine these hypotheses - did not have an overt focus on diet, reducing the likelihood of participants reporting socially desirable answers. It is recommended that parents report dietary intake for children up to 10 years of age to obtain reliable information [21]. We considered a range of potential confounders but there remains the possibility of residual confounding.

Our findings support those of Miller et al., who reported no significant differences between skippers and nonskippers in academic performance, assessed using standardized tests, or classroom behavior over 10 years among children from the USA [7]. In that study some children who ate breakfast may have been misclassified as breakfast skippers as breakfast was defined as eating breakfast with the family. To our knowledge, that is the only other study to examine the longer-term effect of skipping breakfast and it is reassuring to replicate the results in another country and a different education system.
There are several potential explanations as to why skipping breakfast was associated with poorer teacherreported academic performance but not with the national standardized tests. Skipping breakfast was weakly associated with reading and numeracy in the national standardized tests but the associations were attenuated after adjusting for SES and other confounders. Residual confounding is a possible reason for the association between skipping breakfast and teacher-reported assessment, which was subjective and may have been influenced by other factors associated with skipping breakfast such as perceptions of the home environment and family support. This highlights the importance of using objective measures of academic performance. It is also possible that some children may perform differently in formal test situations than in other teacher-assessed classroom tests and assignments. The children were not all enrolled in the same year of school, therefore, the NAPLAN assessments were completed over 3 years. Reassuringly, the proportions of skippers and nonskippers who completed the NAPLAN tests during each year were very similar, so should not have affected the association between skipping breakfast and academic performance.

In Australia, the Government does not fund school food assistance programs, such as free or subsidized lunches. Some schools do have breakfast programs, which are often funded by non-Government organizations, such as the Red Cross and Foodbank Australia [22]. Program delivery such as frequency, foods provided and eligibility varies by school. It is not known whether children in this study participated in a school breakfast program. The breakfast question asked whether breakfast was consumed that day and should include breakfast consumed at home, school or other locations.

The prevalence of skipping breakfast was lower than in other international studies using national data $[9,10,23]$ with only $10 \%$ of children skipping breakfast at least once. This could be explained by the young age of our cohort, as skipping breakfast has been shown to increase with age $[9,24]$ and previous studies included older children (aged 9-14 years old). It is difficult to compare studies due to the different age groups studied and methods used to define breakfast. However, the percentage of children who skipped breakfast is similar to national prevalence estimates from the 2011-12 Australian National Nutrition and Physical Activity Survey, where skipping breakfast was defined using two 24-h recalls [25]. In that study $8 \%$ of boys aged 4-8 years and 14\% of boys aged 9-11 years skipped breakfast on at least one of the 2 days. Among girls $9 \%$ of 4-8 year olds and $14 \%$ of 9-11 year olds skipped breakfast on at least 1 day [25]. There is no consensus on the best method to assess breakfast. Short questions 
referring to breakfast consumption on the current day (as used here) are less prone to recall bias but may not capture usual eating patterns. Other studies have used a meal identified as breakfast in a 24-h recall [9]; eating or drinking something at home before school [10]; and eating within 2 hours of getting up [23].

Most studies only assess whether breakfast was eaten and rarely examine the quality of the breakfast. Further research is needed to determine whether certain breakfast types are more beneficial for cognitive performance. A recent systematic review, of studies conducted with children, adolescents and adults, reported there is emerging evidence that breakfast with a low postprandial glycemic response (produces a relatively small increase in blood glucose) has a beneficial effect on cognitive performance [26] but more well-designed studies are needed to determine the ideal breakfast composition. Further research is also needed to determine whether the association between skipping breakfast and academic performance differs by age and whether there are particular ages at which skipping breakfast has greater impacts on academic performance.

\section{Conclusion}

In this national sample of Australian children, few were skipping breakfast at 8-9 years of age. Breakfast skippers had poorer teacher-reported academic performance 2 years later than those who ate breakfast, but the differences in standardized national tests were small and attenuated after adjusting for SES. It is important to use objective measures of academic performance in further studies, otherwise false conclusions may drive unnecessary and costly interventions. The results from our study and well-designed randomized trials examining the effects of school breakfast programs on academic performance [4-6] suggest that, at a population level, public policy to provide breakfast to all elementary-school aged children may not result in improved education outcomes. However, our findings may not apply to populations with a high proportion of children who regularly go without breakfast.

\section{Additional file}

Additional file 1: Figure S1. Time line showing the data collection periods for the Longitudinal Study of Australian children. Table S1. Differences between children who were included and excluded from the analyses. Table S2. Cross-sectional associations between skipping breakfast aged 8-9 years and teacher-reported academic performance aged 8-9 years ( $N=2056$ ). Table S3. Cross-sectional associations between skipping breakfast aged 8-9 years and teacher-reported behavior aged 8-9 years $(N=2054)$. (PDF 526 kb)

\section{Abbreviations}

LSAC: Longitudinal Study of Australian Children; NAPLAN: National Assessment Program: Literacy And Numeracy; SDQ: Strengths and Difficulties Questionnaire: SES: Socioeconomic status

\section{Acknowledgements}

This paper uses unit record data from Growing Up in Australia, the Longitudinal Study of Australian Children. The study is conducted in partnership between the Department of Families, Housing, Community Services and Indigenous Affairs (FaHCSIA), the Australian Institute of Family Studies (AIFS) and the Australian Bureau of Statistics (ABS). The findings and views reported in this paper are those of the authors and should not be attributed to FaHCSIA, AIFS or the ABS.

\section{Funding}

The analysis for this study was funded by an Australian National Heart Foundation Grant in Aid (G12H6431). KJS (APP1072516), LB (APP1034482), MW (APP1046518) and AJV (APP1008299) were supported by National Health and Medical Research Council Fellowships. SAM was supported by an Australian Research Council fellowship (FT100100581). SLG was supported by National Heart Foundation of Australia Fellowships (PH 11H 6047 and FLF 100446). Research at the Murdoch Childrens Research Institute is supported by the Victorian Government's Operational Infrastructure Program.

The funding bodies had no role in the design of the study or collection, analysis, or interpretation of the data, or the writing of the manuscript.

\section{Availability of data and materials}

The data that support the findings of this study are available from the Australian Institute of Family Studies but restrictions apply to the availability of these data, which were used under license for the current study, and so are not publicly available. Data are however available from the authors upon reasonable request and with permission of the Australian Institute of Family Studies.

\section{Authors' contributions}

KJS, MW and AJV designed the research; KJS and MCB analyzed data; LB provided statistical support; KJS wrote the paper; LB, SAM, SLG, MCB, MW and AJV critically revised the paper; KJS had primary responsibility for final content. All authors read and approved the final manuscript.

\section{Ethics approval and consent to participate}

The analysis of confidentialized LSAC data had the approval of the Australian Institute of Family Studies ethic committee. Consent to participate in the study was given by a parent at wave 1 and permission to link with the child's NAPLAN results at wave 3 (or wave 4 , if wave 3 was skipped).

\section{Consent for publication}

Not applicable

\section{Competing interests}

The authors declare that they have no competing interests.

\section{Publisher's Note}

Springer Nature remains neutral with regard to jurisdictional claims in published maps and institutional affiliations.

\section{Author details}

${ }^{1}$ Menzies Institute for Medical Research, University of Tasmania, Private Bag 23, Hobart, TAS 7000, Australia. ${ }^{2}$ Institute for Physical Activity and Nutrition, School of Exercise and Nutrition Sciences, Deakin University, Melbourne, Australia. ${ }^{3}$ Murdoch Childrens Research Institute, Melbourne, Australia. ${ }^{4}$ Department of Paediatrics, The University of Melbourne, Melbourne, Australia. ${ }^{5}$ Department of Paediatrics and The Liggins Institute, The University of Auckland, Auckland, New Zealand.

Received: 11 August 2016 Accepted: 17 November 2017

Published online: 06 December 2017

\section{References}

1. Adolphus K, Lawton CL, Dye L. The effects of breakfast on behavior and academic performance in children and adolescents. Front Hum Neurosci. 2013;7:425.

2. Hoyland A, Dye L, Lawton CL. A systematic review of the effect of breakfast on the cognitive performance of children and adolescents. Nutr Res Rev. 2009;22(2):220-43. 
3. Rampersaud GC, Pereira MA, Girard BL, Adams J, Metzl JD. Breakfast habits, nutritional status, body weight, and academic performance in children and adolescents. J Am Diet Assoc. 2005;105(5):743-60.

4. Bernstein L, McLaughlin J, Crepinsek M, Daft L. Evaluation of the school breakfast program pilot project: final report. In: Singh A, editor. Nutrition assistance program report series. Alexandria: U.S. Department of Agriculture, Food and Nutrition Service, Office of Analysis, Nutrition, and Evaluation; 2004

5. Mhurchu CN, Gorton D, Turley M, Jiang Y, Michie J, Maddison R, Hattie J. Effects of a free school breakfast programme on children's attendance, academic achievement and short-term hunger: results from a steppedwedge, cluster randomised controlled trial. J Epidemiol Community Health. 2013;67(3):257-64.

6. Murphy S, Moore GF, Tapper K, Lynch R, Clarke R, Raisanen L, Desousa C, Moore L. Free healthy breakfasts in primary schools: a cluster randomised controlled trial of a policy intervention in Wales, UK. Public Health Nutr. 2011;14(2):219-26.

7. Miller DP, Waldfogel J, Han WJ. Family meals and child academic and behavioral outcomes. Child Dev. 2012;83(6):2104-20.

8. Bradley RH, Corwyn RF. Socioeconomic status and child development. Annu Rev Psychol. 2002;53:371-99.

9. Deshmukh-Taskar PR, Nicklas TA, O'Neil CE, Keast DR, Radcliffe JD, Cho S. The relationship of breakfast skipping and type of breakfast consumption with nutrient intake and weight status in children and adolescents: the national health and nutrition examination survey 1999-2006. J Am Diet Assoc. 2010;110(6):869-78.

10. Utter J, Scragg R, Mhurchu CN, Schaaf D. At home breakfast consumption among New Zealand children: associations with body mass index and related nutrition behaviors. J Am Diet Assoc. 2007;107(4):570-6.

11. Soloff C, Lawrence D, Johnstone R. The Longitudinal Study of Australian Children: an Australian government initiative. LSAC technical reference paper no. 1: sample design: Australian Government, Australian Institute of Family Studies; 2005.

12. Soloff C, Millward C, Sanson A, the LSAC Consortium Advisory Group, and Sampling Design Team. LSAC discussion paper no. 2. Proposed study design and wave 1 data collection: Australian Institute of Family Studies Commonwealth of Australia; 2003.

13. Daraganova G, Edwards B, Sipthort M. Using National Assessment ProgramLiteracy and Numeracy (NAPLAN) data in the Longitudinal Study of Australian Children (LSAC). Canberra: Australian Institute of Family Studies; 2013.

14. Goodman A, Lamping DL, Ploubidis GB. When to use broader internalising and externalising subscales instead of the hypothesised five subscales on the Strengths and Difficulties Questionnaire (SDQ): data from British parents, teachers and children. J Abnorm Child Psychol. 2010;38(8):1179-91.

15. Lucas N, Bayer JK, Gold L, Mensah FK, Canterford L, Wake M, Westrupp EM, Nicholson JM. The cost of healthcare for children with mental health difficulties. Aust N Z J Psychiatry. 2013;47(9):849-58.

16. Dillon-Wallace JA, McDonagh SH, Fordham LA. Maternal employment, work experiences, and financial well-being of Australian mothers who care for young children with special health care needs. J Fam Issues. 2014; ePub ahead of print:1-22.

17. Greenland S. Modeling and variable selection in epidemiologic analysis. Am J Public Health. 1989;79(3):340-9.

18. Blizzard CL, Quinn SJ, Canary JD, Hosmer DW. Log-link regression models for ordinal responses. Open J Stat. 2013:3:16-25.

19. Seaman SR, White IR, Copas AJ, Li L. Combining multiple imputation and inverse-probability weighting. Biometrics. 2012;68(1):129-37.

20. Australian Curriculum, Assessment and Reporting Authority. NAPLAN achievement in reading, writing, language conventions and numeracy: National Report for 2010. Sydney: ACARA Australian Curriculum Assessment and Reporting Authority; 2010.

21. Magarey A, Watson J, Golley R, Burrows T, Sutherland R, McNaughton S, Denney-Wilson E, Campbell K, Collins C. Assessing dietary intake in children and adolescents: considerations and recommendations for obesity research. Int J Pediatr Obes. 2011;6(1):2-11.

22. Lindberg R, Whelan J, Lawrence M, Gold L, Friel S. Still serving hot soup? Two hundred years of a charitable food sector in Australia: a narrative review. Aust N Z J Public Health. 2015;39(4):358-65.

23. Manios Y, Moschonis G, Androutsos O, Filippou C, Van Lippevelde W, Vik FN, te Velde SJ, Jan N, Dossegger A, Bere E, et al. Family sociodemographic characteristics as correlates of children's breakfast habits and weight status in eight European countries. The ENERGY (EuropeaN Energy balance research to prevent excessive weight gain among youth) project. Public Health Nutr. 2015;18(5):774-83.

24. McLennan W, Podger A. National Nutrition Survey. Selected highlights Australia 1995. Cat no. 4802.0. Canberra: Australia Bureau of Statistics; 1997.

25. Smith KJ, Breslin MC, Gall SL, McNaughton SA, Blizzard L, Venn AJ. Skipping breakfast among Australian children and adolescents; findings from the 2011-12 National Nutrition and Physical Activity Survey. Aust N Z J Public Health. 2017. Accepted for publication 5/7/17.

26. Edefonti $\mathrm{V}$, Rosato $\mathrm{V}$, Parpinel $M$, Nebbia G, Fiorica L, Fossali E, Ferraroni M, Decarli A, Agostoni $C$. The effect of breakfast composition and energy contribution on cognitive and academic performance: a systematic review. Am J Clin Nutr. 2014;100:626

\section{Submit your next manuscript to BioMed Central and we will help you at every step:}

- We accept pre-submission inquiries

- Our selector tool helps you to find the most relevant journal

- We provide round the clock customer support

- Convenient online submission

- Thorough peer review

- Inclusion in PubMed and all major indexing services

- Maximum visibility for your research

Submit your manuscript at www.biomedcentral.com/submit
) Biomed Central 